\title{
Association of LTF, ENAM, and AMELX polymorphisms with dental caries susceptibility: A meta-analysis
}

Roohollah Sharifi

Kermanshah University of Medical Sciences

Sajjad Jahedi

Kermanshah University of Medical Sciences

Hamid Reza Mozaffari

Kermanshah University of Medical Sciences

Mohammad Moslem Imani

Kermanshah University of Medical Sciences

Masuod Sadeghi ( $\nabla$ sadeghi_mbrc@yahoo.com )

Kermanshah University of Medical Sciences https://orcid.org/0000-0002-3586-3012

Amin Golshah

Kermanshah University of Medical Sciences

Hedaiat Moradpoor

Kermanshah University of Medical Sciences

Mohsen Safaei

Kermanshah University of Medical Sciences

\section{Research article}

Keywords: Dental caries, polymorphism, Lactotransferrin, enamelin, amelogenin X

Posted Date: January 8th, 2020

DOI: https://doi.org/10.21203/rs.2.20240/v1

License: (1) This work is licensed under a Creative Commons Attribution 4.0 International License.

Read Full License

Version of Record: A version of this preprint was published at BMC Oral Health on May 6th, 2020. See the published version at https://doi.org/10.1186/s12903-020-01121-7. 


\section{Abstract}

Background This meta-analysis evaluated the association of LTF, ENAM, and AMELX polymorphisms with dental caries susceptibility.

Methods We searched the Scopus, PubMed/Medline, Web of Science, and Cochrane Library databases to retrieve articles published by October 2019. Review Manager 5.3 software was used to estimate the odds ratios (ORs) and $95 \%$ confidence intervals (Cls). The results of publication bias tests were retrieved by Comprehensive Meta-Analysis 2.0 software.

Results A total of 150 relevant records were identified; out of which, 16 were entered into the analysis (4 studies assessed LTF, 11 ENAM, and 11 AMELX polymorphisms). Of all polymorphisms, there was a significant association only between ENAM rs3796704 polymorphism and dental caries susceptibility. Both ENAM rs3796704 and AMELX rs17878486 polymorphisms had a significant association with dental caries risk in the Caucasian ethnicity and the studies including caries-free control group.

Conclusions The results of this meta-analysis showed that the $\mathrm{G}$ allele and the GG genotype of ENAM rs3796704 were associated with an increased risk of caries in the case group compared with the control group. But there was no association between LTF rs1126478, ENAM (rs1264848 and rs3796703), and AMELX (rs946252, rs17878486, and rs2106416) polymorphisms and dental caries susceptibility.

\section{Highlights}

1. There was an association between ENAM rs3796704 polymorphism and the risk of dental caries.

2. There was no association between polymorphisms of LTF(rs1126478), ENAM (rs1264848 and rs3796703), and $A M E L X$ (rs946252, rs17878486, and rs2106416) and dental caries susceptibility.

\section{Introduction}

Dental caries can significantly affect the general health and quality of life in the modern world [1]. Dental caries develops following demineralization of tooth structure and often results in pulpal and periapical inflammation, and subsequent pain, infection and tooth loss [1,2]. Some environmental conditions and population groups may contribute to higher incidence of dental caries [2]. Environmental risk factors may also affect dental caries development [3]. Although exposed to the same environmental conditions, some patients may be more sensitive or more resistant to dental caries than others; such differences may be due to genetic factors in dental caries etiopathogenesis [4]. New findings raised possibilities of presence of associations between genetic factors and dental caries [5]. The etiology of dental caries involves complex interactions between genetic and environmental factors. Three prevalent genes are reportedly involved in development of dental caries namely the lactotransferrin (LTF), enamelin (ENAM), and amelogenin X (AMELX). The rs1126478 polymorphism of LTF (a saliva protein gene) produces a shift from arginine to lysine at amino acid position 47 in the antimicrobial region, and presents transcriptional activation activity [6]. LTF can decrease the lipopolysaccharide-activated innate immune response, 
regulate the adaptive immune system [7], and play a significant role in physiological homoeostasis, which is in turn related to disease development [8]. ENAM (a member of P/Q-rich secretory calciumbinding phosphoprotein cluster genes) is located on chromosome 4q 13.3 [9]. The gene encodes the protein enamelin, which is the largest protein found in the enamel matrix and is involved in dental enamel mineralization and its structural organization [10]. AMELX is an essential gene that produces amelogenin as the main protein of dental enamel during the secretion stage of amelogenesis [11]. AMELX polymorphisms result in distinct alternations in enamel microstructure [12]. Therefore, these polymorphisms play a critical role in regulation of mineralization and enamel thickness [13]. The association between the mutations of LTF, ENAM, and AMELX genes and dental caries susceptibility has been shown in some studies $[5,14,15]$. Therefore, we aimed to assess the association of polymorphisms of these genes and the risk of dental caries in a meta-analysis of case-control studies.

\section{Materials And Methods}

\section{Search strategy and study selection}

One author systematically searched the PubMed/Medline, Web of Science, Cochrane Library, and Scopus databases to retrieve articles published by October 2019 without publication period, language, and patient's age restrictions. The search terms or keywords were ("lactotransferrin" or "lactoferrin" or "LTF" or "enamelin" or "ENAM" or "amelogenin X" or "AMELX") and ("dental caries" or "caries" or "decay") and ("gene" or polymorphism* or variant* or genetic*). In addition, the references of the retrieved articles related to the topic including original and review articles were searched to make sure that no study was missed. After article retrieval, another author assessed the titles and abstracts of the articles related to the topic; subsequently, the full-texts of the articles that met our eligibility criteria were downloaded and screened. After screening, the exclusion reason was recorded for any study removed, and the disagreements between the authors were resolved by another author.

\section{Eligibility criteria}

The inclusion criteria were as follows: (I) studies including two independent groups (case group with caries or high caries and caries-free control group or with low/very low caries) without age restriction, (II) studies with any defined Decayed, Missing, and Filled Teeth (DMFT) score for the two groups, (III) studies including one or more polymorphisms of $L T F, E N A M$, and AMELX genes with a minimum of two relevant studies for the analysis; for example, four studies assessed LTF rs1126478, ENAM rs1264848, ENAM rs3796704, ENAM rs3796703, AMELX rs946252, AMELX rs17878486, AMELX rs6639060, and AMELX rs2106416 polymorphisms; and (IV) patients and controls had to have no genetic diseases, chronic illnesses, or other disorders. We excluded irrelevant studies, studies without sufficient data for analysis, studies without a control group, studies including less than 20 individuals in each group, duplicate studies, animal studies, case reports, conference papers, reviews, and systematic reviews. 


\section{Data abstraction}

Two authors independently abstracted the data of the studies analyzed in the meta-analysis. The data from each study, including first author, publication year, country of residence of the included individuals, ethnicity, mean age of individuals in the two groups, age group of individuals in each study, genotyping method, DMFT score of the two groups, and type of reported polymorphism (s) in each study, were extracted and analyzed.

\section{Statistical analysis}

Review Manager 5.3 (RevMan 5.3) software was applied to compute the odds ratios (ORs) and 95\% confidence intervals (Cls). To estimate the significance of the pooled OR by the $\mathrm{Z}$ test, a $p$-value (twosided) $<0.05$ was considered significant. The $\mathrm{I}^{2}$ statistic was used to estimate heterogeneity. A $p<0.1$ or $I^{2}>50 \%$ indicated a significant heterogeneity and we used the random-effects model for such cases; if not, the fixed-effects model was used. The publication bias across the studies was assessed using the Egger's and Begg's tests. If $p<0.05$ (two-sided) for both tests or one, there was a significant degree of publication bias. In order to evaluate the stability/consistency of the results, the sensitivity analysis with both "the removal of one study" and "cumulative analysis" was performed. The results of these tests were retrieved by Comprehensive Meta-Analysis 2.0 (CMA 2.0) software.

\section{Results}

\section{Study selection}

A total of 150 records were identified in the databases; after removing the duplicates and irrelevant records, 29 full-text articles were evaluated for eligibility (Figure 1). Next, 13 articles were excluded with reasons: two studies were systematic reviews, two studies were reviews, three studies lacked sufficient data, two studies had no control group, three studies did not report any of the mentioned polymorphisms in this meta-analysis and did not have any known polymorphism either, and one study reported rs1126478 polymorphism with less than 20 individuals in each group. Finally, 16 studies were entered into the analysis.

\section{Study characteristics}

The characteristics of 16 studies included in this meta-analysis are presented in Table 1. The articles had been published from 2008 to 2019. Eleven studies had been conducted on Caucasians [12,14-23], four studies had been conducted on Asians [5,13,24,25], and one on mixed [11] ethnicities. Eleven studies evaluated children $[5,11,13-19,21,25]$, three studies evaluated adults $[20,22,24]$, and two studies evaluated 
both adults and children [12,23]. Four studies had assessed LTF rs1126478 in 1556 cases and 1106 controls $[5,16,19,25]$. Five studies had assessed ENAM rs 1264848 in 934 cases and 600 controls $[11,14,18,21,23]$. Four studies had assessed ENAM rs3796704 in 574 cases and 533 controls $[11,18,22,23]$. Two studies had assessed ENAM rs3796703 in 585 cases and 567 controls [5,13]. Three studies had assessed $A M E L X$ rs946252 in 151 cases and 147 controls [11,12,18]. Four studies had assessed $A M E L X$ rs 17878486 in 249 cases and 193 controls $[11,15,18,24]$. Two studies had assessed AMELX rs6639060 in 157 cases and 144 controls [13,20], and two studies had assessed AMELX rs2106416 in 175 cases and 110 controls [13,17]. One study [17] included two subsets. The genotyping method in all studies was based on polymerase chain reaction (PCR). The controls in six studies $[11,17,20-22,24]$ had low/very low rate of dental caries and others were caries-free. In addition, the two groups in the studies were introduced as the caries group versus the caries-free group, or the high-caries group versus the low/very low caries group.

The genotype prevalence of each polymorphism included in each study in both case and control groups and the $p$-value for the Hardy-Weinberg equilibrium (HWE) for the controls are shown in Table 2. The controls in three studies $[11,12,20]$ had a deviation from the HWE $(P<0.05)$.

\section{Pooled analysis}

Table 3 shows the results of pooled analysis of each polymorphism based on five genetic models. Among the polymorphisms, only the G allele [OR=1.38; 95\%Cl: $1.08,1.76 ; P=0.009 ; I^{2}=27 \%\left(P_{\text {heterogeneity }}\right.$ or $\left.\mathrm{P}_{\mathrm{h}}=0.25\right)$ ] and the GG genotype [OR=1.41;95\%Cl: $\left.\left.1.06,1.87 ; P=0.02 ; I^{2}=18,\left(P_{h}=0.30\right)\right]\right)$ of ENAM rs3796704 had an elevated risk in the case group compared with the control group. In addition, the funnel plots of each polymorphism are presented in the Supplementary file. Therefore, there was a significant association between ENAM rs3796704 polymorphism and dental caries susceptibility.

\section{Subgroup analysis}

Table 4 identifies the subgroup analyses based on the ethnicity, age group, and the control group for each polymorphism and in five genetic models. The results showed that the $\mathrm{G}$ allele and the $\mathrm{GG}$ and $\mathrm{AG}$ genotypes of ENAM rs3796704 had an elevated risk in the case group compared with the control group in the Caucasian ethnicity; whereas in studies with a caries-free control group, the $\mathrm{G}$ allele and GG genotype had an elevated risk in the case group compared with the control group. In addition, the T allele, and TT and CT genotypes of AMELX rs17878486 polymorphism had an elevated risk in the case group compared with the control group in mixed ethnicity and studies with a caries-free control group. Therefore, there was a significant association between both polymorphisms of ENAM rs3796704 and $A M E L X$ rs 17878486 and dental caries susceptibility in the Caucasian ethnicity and studies including caries-free individuals as the control group.

\section{Sensitivity analysis}


One study [18] was omitted from the analysis of AMELX rs17878486 because the outlier data and the results illustrated that by deleting this study, the CT [OR=3.07; 95\% Cl: $1.36,6.94 ; P=0.007 ; I^{2}=0 \%$ $\left.\left(P_{h}=0.37\right)\right]$ and CT + TT [OR= 5.72; 95\%Cl: 2.83, 11.59; $\left.P=<0.00001 ; I^{2}=21 \%\left(P_{h}=0.0 .28\right)\right]$ genotypes in dental caries patients were significantly superior to controls and with a low heterogeneity, respectively (Table 3). In addition, other sensitivity analyses including "one study excluded" and "cumulative analysis" were performed and the previous results did not change qualitatively. Although the genotype distribution of the controls in three studies $[11,12,20]$ did not follow the HWE, these analyses reported that the pooled ORs based on all genetic models were steady.

\section{Publication bias}

Both Egger's and Begg's tests were done on the previous pooled analyses with a minimum of three studies (Figure 2). The results revealed a publication bias regarding GG vs. AA, AG vs. AA, and AG + GG vs. AA models of $L T F$ rs 1126478 polymorphism (Begg's test: $P<0.05$ ) and also T vs. $C$ and CT + TT vs. CC models of $A M E L X$ rs2106416 polymorphism (Begg's test: $P<0.05$ ).

\section{Discussion}

The effect of environmental risk factors [26] and genetic predisposition [27] on development of caries has been well identified. This meta-analysis assessed the association between the common polymorphisms of LTF, ENAM, and AMELX and the risk of dental caries. The findings showed that ENAM rs3796704 polymorphism had an increased risk in the case group compared with the control group especially in the Caucasian ethnicity and studies with caries-free individuals as the control group.

The prevalence of LTF polymorphisms differs among various ethnicities [28]. The genotypes related to LTF level are associated with decreased function and this may lead to decreased defense against infection with stronger stimuli for granulocyte activation and desorption, leading to greater LTF release [28]. Four studies $[5,16,19,25]$ included in this meta-analysis assessed LTF rs 1126478 polymorphism. However, none of them found any association between this polymorphism and dental caries susceptibility. In addition, the subgroup analysis in this meta-analysis did not find any association between this polymorphism and dental caries risk. Thus, we can exclude LTF rs 1126478 polymorphism as a risk factor for dental caries; however, more accurate confirmation of results requires further research through larger studies on different ethnicities.

AMELX is the most significant factor for development of normal enamel [24] and AMELX aberration predominantly causes mineralization defects and congenital disorders such as amelogenesis imperfecta [29]. Therefore, some researchers suggest that genetic variations contribute to structural changes of the enamel and may create more levels of mineral loss, bacterial extension or biofilm deposition [30]. In the 
present meta-analysis on AMELX rs946252, AMELX rs17878486, AMELX rs6639060, and AMELX rs2106416 polymorphisms, none of them was associated with the risk of dental caries. However, the sensitivity analysis revealed that AMELX rs17878486 polymorphism could be a risk factor for dental caries but the ethnicity and type of selected controls were the effective factors on the association between AMELX rs17878486 polymorphism and risk of dental caries. In addition, two studies included in this meta-analysis $[11,15]$ showed an association between AMELX rs17878486 polymorphism and dental caries susceptibility. Therefore, it may point to the role of AMELX rs17878486 polymorphism in development of dental caries more than others.

ENAM gene may also play a role in enamel formation [31] and any change in genes that encode enamel proteins may lead to enamel malformation [32]. Among studies on ENAM polymorphisms included in this meta-analysis, one study on Saudi patients [23] reported an elevated risk of ENAM rs1264848 polymorphism and another study on Polish children [14] showed the protective role of ENAM rs 1264848 polymorphism in dental caries, which was confirmed by Abbasoğlu et al, in their study on Turkish children [33]. Also, one study [23] reported an elevated risk of ENAM rs3796704 polymorphism and another study [5] showed an elevated risk of ENAM rs3796703 polymorphism in dental caries patients compared with controls. One research [21] reported that there were significant differences in the minor allele frequency between the Poles and Czechs populations. In addition, the sensitivity analysis confirmed the effect of ethnicity and type of control group on the association of ENAM rs3796704 and risk of dental caries. Bayram and colleagues [34] showed that ENAM polymorphisms may affect the development of enamel and these effects may be different between primary and permanent dentitions.

Small number of studies included in each analysis and different DMFT scores for selecting the cases and controls between the studies were two important limitations of the present meta-analysis. However, in most analyses, the heterogeneity was low and there was no publication bias.

\section{Conclusions}

The findings of this meta-analysis confirmed that the G allele and the GG genotype of ENAM rs3796704 polymorphism were associated with an elevated risk of caries in the case group compared with the control group. But there was no association between LTF rs1126478, ENAM rs1264848, ENAM rs3796703, AMELX rs946252, AMELX rs17878486, and AMELX rs2106416 polymorphisms and dental caries susceptibility. However, subgroup analysis showed an association between ENAM rs3796704 and AMELX rs 17878486 polymorphisms and dental caries susceptibility in the Caucasian ethnicity and studies including caries-free individuals as the control group. In addition, sensitivity analysis showed an increased risk of AMELX rs17878486 polymorphism in the case group compared with the control group.

\section{Abbreviations}

LTF: Lactotransferrin 
ENAM: Enamelin

AMELX: Amelogenin X

OR: Odds ratio

HWE: Hardy-Weinberg equilibrium

Cl: Confidence interval

DMFT: Decayed, Missing, and Filled Teeth

\section{Declarations}

\section{Ethics approval and consent to participate}

This study was approved by the Ethics Committee of Kermanshah University of Medical Sciences, Kermanshah, Iran (approval number: IR.KUMS.REC.1398.795). In addition, consent to participate form was signed by each participant in the study.

\section{Consent to publish}

Not applicable.

\section{Availability of data and materials}

The datasets used and/or analysed during the current study available from the corresponding author on reasonable request.

\section{Competing interests}

The authors declare that they have no competing interests.

\section{Funding}

This study was funded by the Research Council of Kermanshah University of Medical Sciences (Grant Number: 980711). The funding body did not contribute to the design of the study, the collection, analysis, and interpretation of data or in writing of the manuscript.

\section{Authors' contributions}

RS and MaS contributed to the conception and design of the work. SJ contributed to the acquisition and analysis of data. HRM, MMI, AG, HM, and MoS contributed to interpretation of data and created new software used in the work. MaS drafted the manuscript and substantively revised the manuscript. All authors read and approved the final manuscript. 
Acknowledgements

This work was performed in partial fulfillment of the requirements for a doctorate degree in General Dentistry (Sajjad Jahedi), in Faculty of Dentistry, Kermanshah University of Medical Sciences, Kermanshah, Iran.

\section{References}

1.

Hunter PB. Risk factors in dental caries. Int Den J. 1988;38:211-7.

2.

Zander A, Sivaneswaran S, Skinner J, Byun R, Jalaludin B. Risk factors for dental caries in small rural and regional Australian communities. Rural Remote Health. 2013;13:2492.

3.

Slayton RL, Cooper ME, Marazita ML. Tuftelin, mutans streptococci, and dental caries susceptibility. J Dent Res. 2005;84:711-4.

4.

Renuka P, Pushpanjali K, Sangeetha R. Review on "Influence of host genes on dental caries. J Dent Med Sci. 2013;4:86-92.

5 .

Wang M, Qin M, Xia B. The association of Enamelin, Lactoferrin, and Tumour necrosis factor alpha gene polymorphisms with high caries susceptibility in Chinese children under 4 years old. Arch Oral Biol. 2017;80:75-81.

6.

Velliyagounder K, Kaplan JB, Furgang D, Legarda D, Diamond G, Parkin RE, Fine DH. One of two human lactoferrin variants exhibits increased antibacterial and transcriptional activation activities and is associated with localized juvenile periodontitis. Infect Immun. 2003;71:6141-7.

7.

Actor JK, Hwang SA, Kruzel ML. Lactoferrin as a natural immune modulator. Curr Pharm Des. 2009;15:1956.

8.

Kruzel ML, Zimecki M, Actor JK. Lactoferrin in a context of inflammation-induced pathology. Front Immunol. 2017;8:1438.

9.

Al-Hashimi N, Sire J-Y, Delgado S. Evolutionary analysis of mammalian enamelin, the largest enamel protein, supports a crucial role for the 32-kDa peptide and reveals selective adaptation in rodents and primates. J Mol Evol. 2009;69:635-56.

10 .

JD

Bartlett

Bartlett JD. Dental enamel development: proteinases and their enamel matrix substrates. ISRN. 
Dent. 2013;2013:684607.

11.

Jeremias F, Koruyucu M, Küchler EC, Bayram M, Tuna EB, Deeley K, Pierri RA, Souza JF, Fragelli CM, Paschoal MA, Gencay K, Seymen F, Caminaga RM, dos Santos-Pinto L, Vieira AR. Genes expressed in dental enamel development are associated with molar-incisor hypomineralization. Arch Oral Biol. 2013;58:1434-42.

12.

Gasse B, Grabar S, Lafont AG, Quinquis L, Opsahl Vital S, Davit-Béal T, Moulis E, Chabadel O, Hennequin M, Courson F, Droz D, Vaysse F, Laboux O, Tassery H, Al-Hashimi N, Boillot A, Carel JC, Treluyer JM, Jeanpierre M, Beldjord C, Sire JY, Chaussain C. Common SNPs of AmelogeninX (AMELX) and dental caries susceptibility. J Dent Res. 2013;92:418 - 24.

13.

Ouryouji K, Imamura Y, Fujigaki Y, Oomori Y, Yanagisawa S, Miyazawa H, Wang P-L. Analysis of mutations in the amelogenin and the enamelin genes in severe caries in Japanese pediatric patients. Pediatric Dent J. 2008;18:79-85.

14.

Gerreth K, Zaorska K, Zabel M, Borysewicz-Lewicka M, Nowicki M. Association of ENAM gene single nucleotide polymorphisms with dental caries in Polish children. Clin Oral Investig. 2016;20:631-6. 15.

Gerreth K, Zaorska K, Zabel M, Borysewicz-Lewicka M, Nowicki M. Chosen single nucleotide polymorphisms (SNPs) of enamel formation genes and dental caries in a population of Polish children. Adv Clin Exp Med. 2017;26:899-905.

16.

Azevedo LF, Pecharki GD, Brancher JA, Cordeiro CA Jr, Medeiros KG, Antunes AA, Arruda ES, Werneck RI, de Azevedo LR, Mazur RF, Moysés SJ, Moysés ST, Faucz FR, Trevilatto PC. Analysis of the association between lactotransferrin (LTF) gene polymorphism and dental caries. J Appl Oral Sci. 2010;18:166-70. 17.

Olszowski T, Adler G, Janiszewska-Olszowska J, Safranow K, Kaczmarczyk M. MBL2, MASP2, AMELX, and ENAM gene polymorphisms and dental caries in Polish children. Oral Dis. 2012;18:389 - 95. 18.

Ergöz N, Seymen F, Gencay K, Tamay Z, Deeley K, Vinski S, Vieira AR. Genetic variation in Ameloblastin is associated with caries in asthmatic children. Eur Arch Paediatr Dent. 2014;15:211-6.

19.

Volckova M, Linhartova PB, Trefna T, Vlazny J, Musilova K, Kukletova M, Kukla L, Holla LI. Lack of association between lactotransferrin polymorphism and dental caries. Caries Res. 2014;48:39-44. 20.

Yildiz G, Ermis RB, Calapoglu NS, Celik EU, Türel GY. Gene-environment Interactions in the Etiology of Dental Caries. J Dent Res. 2016;95:74 - 9.

21. 
Borilova Linhartova P, Deissova T, Musilova K, Zackova L, Kukletova M, Kukla L, Izakovicova Holla L. Lack of association between ENAM gene polymorphism and dental caries in primary and permanent teeth in Czech children. Clin Oral Investig. 2018;22:1873-7.

22.

Koohpeima F, Hashemi-Gorji F, Mokhtari MJ. Evaluation of caries experience in two genders and ENAM polymorphism in Iranian adults. Meta Gene. 2018;17:78-81.

23.

Devang Divakar D, Alanazi SAS, Assiri MYA, Mohammed Halawani S, Zaid Alshehri S, Ahmed Saeed AlAmri S, Mustafa M. Association between ENAM polymorphisms and dental caries in children. Saudi J Biol Sci. 2019;26:730-5.

24.

Kang SW, Yoon I, Lee HW, Cho J. Association between AMELX polymorphisms and dental caries in Koreans. Oral Dis. 2011;17:399-406.

25.

Wang M, Qin M. Lack of association between LTF gene polymorphisms and different caries status in primary dentition. Oral Dis. 2018;24:1545-53.

26.

Peres KG, Peres MA, Araujo CL, Menezes AM, Hallal PC. Social and dental status along the life course and oral health impacts in adolescents: a population-based birth cohort. Health Qual Life Outcomes. $2009 ; 7: 95$.

227.

Werneck RI, Mira MT, Trevilatto PC. A critical review: an overview of genetic influence on dental caries. Oral Dis. 2010;16:613-23.

28.

Videm V, Dahl H, Wålberg LE, Wiseth R. Functional polymorphisms in the LTF gene and risk of coronary artery stenosis. Hum Immunol. 2012;73:554-9.

29.

Greene SR, Yuan ZA, Wright JT, Amjad H, Abrams WR, Buchanan JA, Trachtenberg DI, Gibson CW. A new frameshift mutation encoding a truncated amelogenin leads to $x$-linked amelogenesis imperfecta. Arch Oral Biol. 2002;47:211-7.

30.

Patir A, Seymen F, Yildirim M, Deeley K, Cooper ME, Marazita ML, Vieira AR. Enamel formation genes are associated with high caries experience in turkish children. Caries Res. 2008;42:394-400.

31.

Kelley JL, Swanson WJ. Dietary change and adaptive evolution of enamelin in humans and among primates. Genetics. 2008;178:1595-603.

32.

Babbitt CC, Warner LR, Fedrigo O, Wall CE, Wray GA. Genomic signatures of diet-related shifts during human origins. Proc Biol Sci. 2011;278:961-9.

33. 
Abbasoğlu Z, Tanboğa I, Küchler EC, Deeley K, Weber M, Kaspar C, Korachi M, Vieira AR. Early childhood caries is associated with genetic variants in enamel formation and immune response genes. Caries Res. 2015;49:70-7.

34.

Bayram M, Deeley K, Reis MF, Trombetta VM, Ruff TD, Sencak RC, Hummel M, Dizak PM, Washam K, Romanos HF, Lips A, Alves G, Costa MC, Granjeiro JM, Antunes LS, Küchler EC, Seymen F, Vieira AR. Genetic influences on dental enamel that impact caries differ between the primary and permanent dentitions. Eur J Oral Sci. 2015;123:327-34.

\section{Figures}



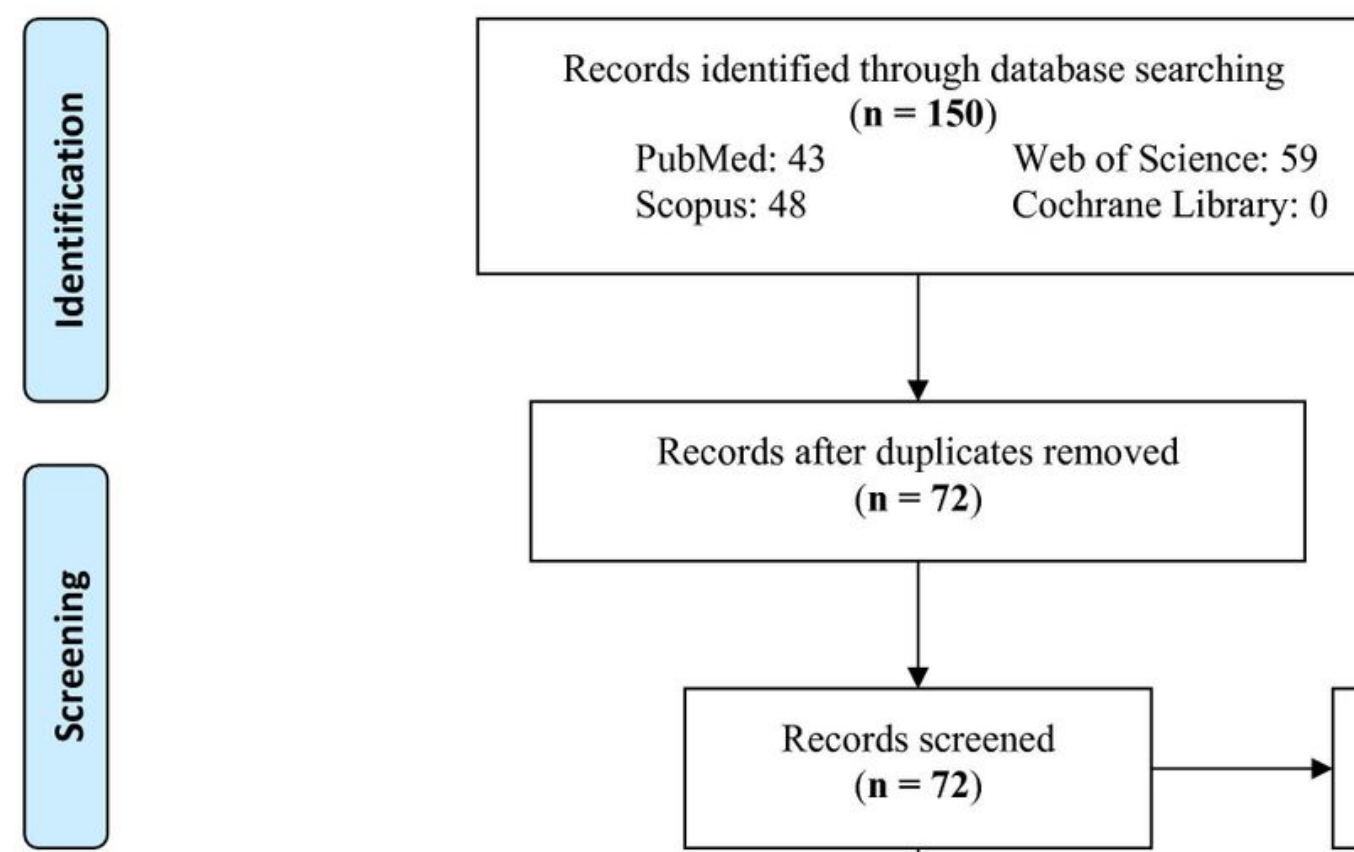

Records after duplicates removed

$$
(\mathbf{n}=72)
$$
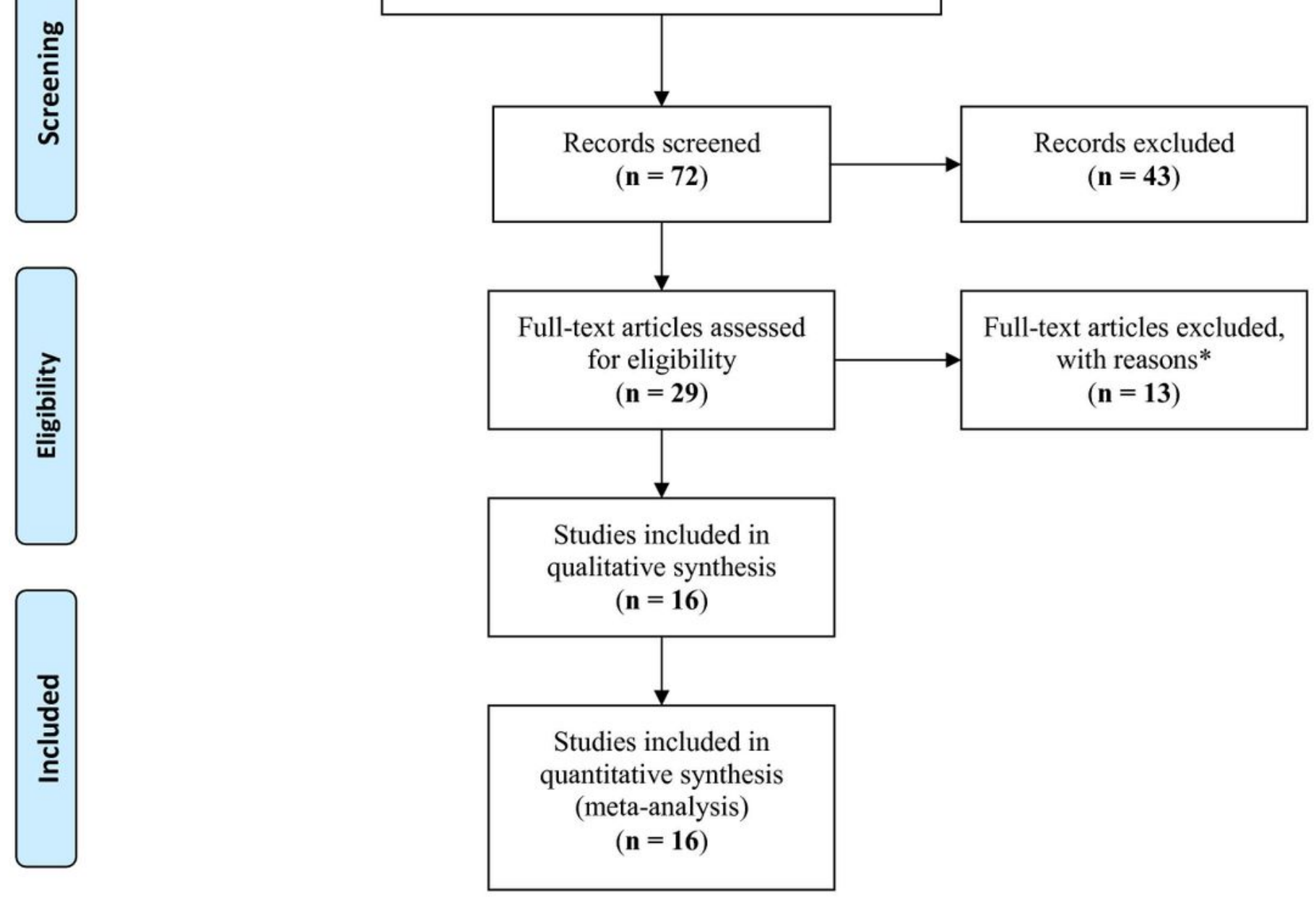

$*_{2} \underline{2}$ studies were systematic reviews, $\underline{2}$ studies were reviews, $\underline{3}$ studies had lack of sufficient data, $\underline{2}$ studies had no control group, $\underline{3}$ studies didn't report any of the mentioned polymorphisms in this meta-analysis nor had known polymorphisms, and 1 study reported rs1126478 polymorphism with less than 20 individuals in each group.

\section{Figure 1}

Flow chart of study selection 

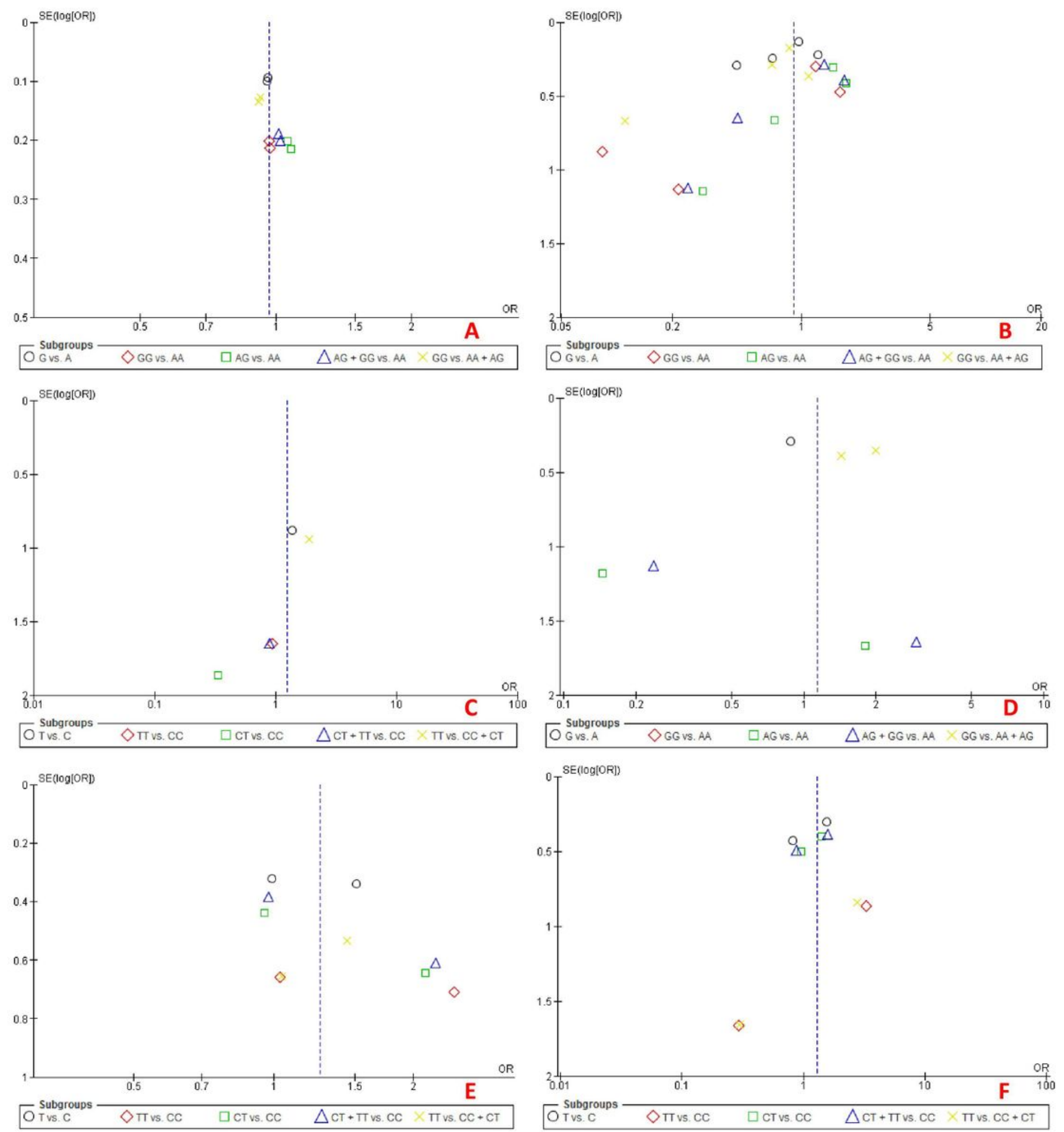

\section{Figure 2}

Funnel plots of the analysis of each polymorphism with a minimum of three studies: A) LTF rs1126478, B) ENAM s1264848, C) ENAM rs3796704, D) AMELX rs946252, E) AMELX rs17878486, and F) AMELX rs2106416 
This is a list of supplementary files associated with this preprint. Click to download.

- Supplement.pdf 